\title{
A JUSTIFICAÇÃO INTERNA E EXTERNA DA MÁXIMA DA PROPORCIONALIDADE COMO ARGUMENTO JURÍDICO NAS OBRAS DE ROBERT ALEXY
}

\author{
Rodrigo Alvares Carneiro ${ }^{1}$
}

\section{RESUMO}

O presente artigo visa investigar como a máxima da proporcionalidade pode ser classificada dentre as categorias apresentadas na Teoria da Argumentação de Robert Alexy. Para tanto, buscou-se um entrelaçamento de conceitos que estão presentes em dois de seus principais livros: Teoria da Argumentação Jurídica e Teoria dos Direitos Fundamentais, através de metodologia teórica, bibliográfica e de caráter qualitativo. Ao fim, constatou-se que a máxima da proporcionalidade, bem como suas máximas parciais, pode estar presente na justificação interna e ser justificada externamente de forma adequada segundo alguns paradigmas apresentados na Teoria da Argumentação Jurídica de Alexy.

Palavras-chave: Robert Alexy. Máxima da proporcionalidade. Teoria da argumentação jurídica. Justificação interna. Justificação externa.

\section{INTERNAL AND EXTERNAL JUSTIFICATION OF THE RULE OF PROPORTIONALITY AS A LEGAL ARGUMENT IN ROBERT ALEXY'S WORKS}

\begin{abstract}
This essay aims to investigate how the rule of proportionality can be classified among the categories presented in Robert Alexy's Theory of Argumentation. In order to achieve this objective, we sought to interlace concepts that are present in two of his main works - Theory of Legal Argumentation and Theory of Constitutional Rights - through theoretical, bibliographic and qualitative methodology. Finally, it was found that the rule of proportionality and its sub-rules can be present in the internal justification and be externally justifiable in a suitable way according to some paradigms presented in Alexy's Theory of Legal Argumentation.
\end{abstract}

Keywords: Robert Alexy. Rule of Proportionality. Theory of Legal Argumentation. Justification Internal. Justification External.

* Mestra em Direito pela Universidade Federal de Santa Maria. Doutoranda em Direito pelo Programa de PósGraduação da Universidade Federal do Rio Grande do Sul, com bolsa CAPES, e membro dos grupos de pesquisa Direitos Fundamentais e Novos Direitos e Sociologia Judiciária, ambos inscritos na plataforma dos grupos de pesquisa do CNPq, sob orientação do Prof. Dr. José Alcebíades de Oliveira Junior. E-mail: francieli.raminelli@gmail.com.

** Mestra em Direito pela Universidade Federal de Santa Maria. Coordenadora do Núcleo de Estudos em Direito Internacional (NEDI) da Faculdade de Direito de Santa Maria (FADISMA). Professora de Direito da Faculdade de Direito de Santa Maria (FADISMA). Doutoranda no Programa de Pós-graduação em Processos e Manifestações Culturais - Universidade Feevale. E-mail: cristianepaulidemenezes@gmail.com. 


\section{INTRODUÇÃO}

O autor alemão Robert Alexy tem sido um dos pensadores mais influentes no direito desde meados do século XX. Sua “Teoria da Argumentação Jurídica”, publicada em 1983, fortaleceu a discussão sobre uma teoria da argumentação no direito. A “Teoria dos Direitos Fundamentais”, por sua vez, publicada em 1985 e com uma segunda edição em 1994, apresentou concepções de princípios e regras que vem sendo utilizadas largamente por diversas cortes constitucionais e pelo próprio $\mathrm{STF}^{3}$. É neste trabalho, também, que Alexy apresenta a máxima da proporcionalidade como um método para solucionar conflitos entre princípios. Porém, em que pese a importância de ambas as obras para o conjunto da teoria alexyana, o autor, nesses dois livros, não traz grandes aprofundamentos de como os conceitos apresentados em um dos escritos poderiam ser lidos através da lente do outro e vice-versa ${ }^{4}$.

Este artigo busca um maior entrelaçamento entre as duas grandes obras de Alexy, ao explorar a proporcionalidade como um argumento jurídico apto de justificação. Dessa forma, pretendese responder a seguinte pergunta: como o uso da máxima da proporcionalidade pode ser analisado dentro da teoria da argumentação jurídica de Alexy? O artigo - que, metodologicamente, é teórico, tem caráter qualitativo e se utiliza do procedimento de análise de conteúdo bibliográfico - pois, tem como objetivo investigar como a máxima da proporcionalidade pode ser categorizada dentre os tipos de argumentos jurídicos de justificação interna e externa. Tal esforço se justifica na medida em que o desenvolvimento do diálogo entre as duas obras permite relevar e aprofundar o entendimento entre conceitos fundamentais do pensamento de Alexy.

\footnotetext{
3 “A máxima da proporcionalidade é um dos “sucessos de exportação” da Ciência Jurídica alemã, além de possuir atrás de si uma trilha, internacional e única, de vitórias. Ela foi recepcionada por várias ordens jurídicas e vale igualmente no Direito da União Europeia e na Convenção Europeia de Direitos Humanos” (KLAT; MEISTER, 2014, p. 24).

${ }^{4}$ Exemplificativamente, o conceito de princípios aparece em "Teoria da Argumentação Jurídica” como sendo "proposições normativas de um alto nível de generalidade" (ALEXY, 2005, p. 238), enquanto em "Teoria dos Direitos Fundamentais" aparece como "mandamento de otimização que são caracterizados por poderem ser satisfeitos em graus variados e pelo fato de que a medida devida de sua satisfação não depende somente das possibilidades fáticas, mas também das possibilidades jurídicas” (ALEXY, 2011, p. 90). Nesse sentido Geremberg (2006, p. 14) afirma que "[...] a teoria de Alexy não é sistemática. Encontrar vínculos entre suas principais obras e entender sua produção intelectual como um todo é difícil, sobretudo, porque apesar de interrelacionados, há um lapso temporal entre seus trabalhos e as revisões que são feitas em um destes, apesar de afetar aos demais, não é acompanhada de uma atualização dos outros pontos que foram, por conseguinte, alterados. Este é o caso da 'Teoria da Argumentação Jurídica', a qual, após as alterações efetuadas na obra ‘Teoria dos Direitos Fundamentais', necessitaria passar por uma revisão e atualização”.
} 


\section{A JUSTIFICAÇÃO INTERNA E EXTERNA DA MÁXIMA DA PROPORCIONALIDADE COMO ARGUMENTO JURÍDICO NAS OBRAS DE ROBERT ALEXY}

Para tanto, o primeiro capítulo de desenvolvimento tratará dos conceitos fundamentais da máxima da proporcionalidade e da justificação interna e externa. Por sua vez, o segundo investigará em quais categorias a máxima da proporcionalidade pode ser classificada.

2 CONCEITOS FUNDAMENTAIS: A MÁXIMA DA PROPORCIONALIDADE E A ARGUMENTAÇÃO JURIDICA

Neste tópico, serão delineadas as noções de máxima da proporcionalidade e de argumentação jurídica no pensamento de Alexy.

\subsection{A máxima da proporcionalidade}

A importância do conceito da máxima (Grundsatz) da proporcionalidade está diretamente conectada à concepção de princípio alexyana. Para Alexy (2011, p. 116), “essa conexão não poderia ser mais estreita: a natureza dos princípios implica a máxima da proporcionalidade, e essa implica aquela”. Isso porque, sendo princípios mandamentos de otimização que devem ser realizados na maior medida possível (ALEXY, 2011, p. 90), e, havendo a possibilidade de que eles colidam entre si - que um proíba e outro autorize determinada conduta - (ALEXY, 2011, p. 93), a proporcionalidade funciona como critério para buscar uma maior racionalização acerca das decisões que buscam definir qual princípio deverá ter precedência sobre outro diante de dadas condições fáticas e jurídicas (ALEXY, 2011, p. 117).

A máxima da proporcionalidade se subdivide em três máximas parciais: adequação, necessidade (mandamento do meio menos gravoso) e proporcionalidade em sentido estrito (mandamento do sopesamento propriamente dito) (ALEXY, 2011, p. 117). As duas primeiras tratam da otimização em face das possibilidades fáticas da decisão, já a outra cuida dos mandamentos de otimização em razão das possibilidades jurídicas (ALEXY, 2011, p. 118). Assim sendo, “as três máximas parciais da máxima da proporcionalidade definem aquilo que deve ser compreendido por 'otimização’ na teoria dos princípios” (ALEXY, 2011, p. 588).

O exame das máximas da adequação e necessidade se refere a uma relação de meio-fim (ALEXY, 2011, p. 588). No entanto, a máxima da adequação funciona como um critério negativo. "Ela elimina meios não adequados. Um tal critério negativo não determina tudo, mas exclui algumas coisas [...] - a saber: aquilo que não é adequado” (ALEXY, 2011, p. 590). A pergunta a ser feita nesse momento é se dada medida está apta para fomentar a realização de

Revista de Teorias da Justiça, da Decisão e da Argumentação Jurídica | e-ISSN: 2525-9644 | Salvador | v. 4 | n. 1 | p. 96 - 118 | 
determinado objetivo revelado por certo princípio, devendo-se excluir as opções não aptas. A máxima da necessidade, por sua vez, "exige que, dentre dois meios aproximadamente adequados, seja escolhido àquele que intervenha de modo menos intenso" (ALEXY, 2011, p. 590). Assim, a decisão deve ser tomada de maneira que a escolha de se proteger determinado princípio interfira da forma menos penosa na realização de outro princípio. Aqui não ocorre uma eliminação de meios como na adequação, mas sim uma eleição dos meios que tutele o princípio de forma a reduzir ao máximo a desconsideração da tutela do princípio concorrente.

A terceira máxima parcial da proporcionalidade é a proporcionalidade em sentido estrito. Neste ponto, máxima parcial da proporcionalidade em sentido estrito e o sopesamento se tornam sinônimas na teoria da Alexy (ALEXY, 2011, p. 594). Alexy (2011) divide a lei do sopesamento em duas: a lei material do sopesamento e a lei epistêmica do sopesamento.

A lei material pode ser expressa da seguinte forma: "quanto maior for o grau de nãosatisfação ou de afetação de um princípio, tanto maior terá que ser a importância da satisfação do outro" (ALEXY, 2011, p. 167). São três as etapas a serem cumpridas nessa lei: $1^{\circ}$ ) avalia-se o grau de não-satisfação ou afetação de um dos princípios; $2^{\circ}$ ) aprecia-se a importância da satisfação do princípio colidente; $3^{\circ}$ ) estima-se se a importância da satisfação do princípio colidente justifica a afetação ou a não-satisfação do outro princípio (ALEXY, 2011, p. 594).

O processo de sopesamento traz como resultado sempre uma norma que tem a estrutura de uma regra (ALEXY, 2011, p. 99). Neste caso é esta regra que será utilizada para solucionar o caso concreto através do processo de subsunção (ALEXY, 2011, p. 102).

A lei epistêmica do sopesamento é apresentada por Alexy (2011, p. 617) nos seguintes termos: “quanto mais pesada for a intervenção em um direito fundamental, tanto maior terá que ser a certeza das premissas nas quais essa intervenção se baseia”. Essa lei procura dar uma dimensão de segurança das premissas que são levantadas na construção do sopesamento. Assim, “diferentemente do que ocorre com a primeira lei, essa segunda lei do sopesamento não está associada à importância material das razões que sustentam a intervenção, mas à sua qualidade epistêmica” (ALEXY, 2011, p. 617). É a qualidade do conhecimento sobre determinado assunto que determinará a qualidade do sopesamento.

Firmados os pressupostos conceituais sobre a máxima da proporcionalidade, cumpre agora esclarecer, ainda que também de forma sucinta, como a teoria da argumentação jurídica de Alexy classifica argumentos jurídicos, para que assim se avance no propósito do trabalho. 


\section{A JUSTIFICAÇÃO INTERNA E EXTERNA DA MÁXIMA DA PROPORCIONALIDADE COMO ARGUMENTO JURÍDICO NAS OBRAS DE ROBERT ALEXY}

\subsection{A argumentação jurídica}

Para Alexy (2005) a argumentação jurídica é uma forma especial do discurso prático geral. Isto porque, para ele em toda argumentação jurídica, assim como na argumentação prática geral, há referências às questões práticas, ou seja, ao que pode ou não ser feito (ALEXY, 2005, p. 210-211). Há também sempre uma pretensão de correção sobre a conduta objeto do discurso (ALEXY, 2005, p. 211).

Sendo um caso especial de discurso prático geral, a argumentação jurídica apresenta como traço fundamental - e especial - em sua estrutura: a justificação de preposições normativas nas decisões jurídicas (ALEXY, 2005, p. 217), há sempre vinculação no discurso ao direito positivo (ALEXY, 2005, p. 210). Para o autor, essa justificação pode ser classificada como justificação interna ou externa. De forma simples, para uma compreensão inicial sobre tal categorização, pode-se dizer que "na justificação interna verifica-se se a decisão se segue logicamente das premissas que se expõem como fundamentação; o objeto da justificação externa é a correção destas premissas” (ALEXY, 2005, p. 217-218).

Cumpre de logo esclarecer que justificação interna e externa se entrelaçam o tempo todo durante a argumentação jurídica, no entanto, enquanto a primeira se preocupa com a conformação lógica entre as premissas expostas na fundamentação, a segunda busca justificar a utilização e a correção dessas premissas que foram utilizadas na justificação interna.

\subsubsection{Justificação interna}

As questões relativas à justificação interna são discutidas de forma mais abundante sob a rubrica de "silogismo jurídico". Este mecanismo, às vezes, é o bastante para resolver certas questões jurídicas (ALEXY, 2005, p. 218). "Na forma mais elementar do silogismo, a premissa maior seria a norma, e a menor, o fato” (PAULA, 2009, p. 05).

Na justificação interna, para Alexy (2005), é preciso que se respeite cinco regras.

A primeira regra diz que "para a fundamentação de uma decisão jurídica deve-se apresentar pelo menos uma norma universal” (ALEXY, 2005, p. 219). Esta norma visa assegurar o princípio (U) da universalidade (princípio da justiça formal), ou seja, busca que todos que estão na mesma “categoria” possam ser tratados igualmente pela decisão judicial.

A segunda regra visa a garantir que essa regra universal seja considerada na decisão juntamente com outras premissas. In verbis: “a decisão jurídica deve seguir-se logicamente ao menos de uma norma universal, junto a outras proposições” (ALEXY, 2005, p. 219). 
Porém, nem sempre o esquema de fundamentação regido apenas pelas duas primeiras regras é suficiente para a resolução de casos mais difíceis, como ocorre quando um texto legal contém diversas alternativas de fato hipotético, ou quando sua aplicação exige complementos de outras normas, e, também, na ocorrência de mais de uma possibilidade de consequência jurídica, ou, ainda, quando há a possibilidade de diversas interpretações para uma mesma norma (ALEXY, 2005, p. 220). Nestes casos, “será necessária outra etapa argumentativa, que decidirá a questão. Isso se dá através da formulação de uma outra regra, com um novo predicado a ser considerado para a subsunção” (PAULA, 2009, p. 07-08). Assim, a terceira regra da justificação interna se revela: "sempre que houver dúvida sobre se A [caso concreto] é um T [hipótese normativa] ou M' [característica relevantes para a incidência da hipótese normativa], deve-se apresentar uma regra que decida a questão” (ALEXY, 2005, p. 223).

Essa etapa, em que há a apresentação de nova regra para decidir se o caso concreto cabe ou não na hipótese normativa, pode se repetir quantas vezes forem necessárias para que torne o argumento não discutível idealmente. É o que busca garantir a quarta regra da justificação interna, que reza: "são necessárias as etapas de desenvolvimento que permitam formular expressões cuja aplicação ao caso em questão não seja discutível” (ALEXY, 2005, p. 224), bem como a quinta regra que prescreve que "deve-se articular o maior número possível de etapas de desenvolvimento” (ALEXY, 2005, p. 224).

\subsubsection{Justificação externa}

Para fundamentar cada premissa dos diferentes níveis do desenvolvimento da estrutura argumentativa "é preciso entrar com profundidade tanto nas especificidades dos fatos como nas particularidades da norma. Isso ocorre na justificação externa, na qual são possíveis todos os argumentos admissíveis no discurso jurídico” (ALEXY, 2005, p. 225).

Dentre as premissas da justificação interna que serão justificadas, Alexy (2005, p. 226) diz que elas podem ser de três tipos: (1) regras de direito positivo, (2) enunciados empíricos ou (3) não serem nem regras de direito positivo nem enunciados empíricos.

Cada um desses grupos terá uma forma diferente de fundamentação. Para as premissas de direito positivo, a fundamentação deverá demonstrar sua conformidade com os critérios de validade do ordenamento (ALEXY, 2005, p. 226). “Na fundamentação de premissas empíricas pode recorrer-se a uma escala completa de formas de proceder que vão desde os métodos das ciências empíricas, passando pelas máximas da presunção racional, até as regras de ônus da 


\section{A JUSTIFICAÇÃO INTERNA E EXTERNA DA MÁXIMA DA PROPORCIONALIDADE COMO ARGUMENTO JURÍDICO NAS OBRAS DE ROBERT ALEXY}

prova no processo” (ALEXY, 2005, p. 226). Porém, tão somente “para a fundamentação das premissas que não são nem enunciados empíricos nem regras de direito positivo aplica-se o que se pode designar de ‘argumentação jurídica’” (ALEXY, 2005, p. 226). Ou seja, a partir de agora, quando se falar em justificação externa por meio da argumentação jurídica, não mais se estará inclusa as justificações de premissas referentes a normas de direito positivos, nem de enunciados empíricos (ALEXY, 2005, p. 227).

Quando se trata da justificação externa, as formas de argumentos e suas regras podem ser classificadas em seis grupos: a argumentação empírica, cânones de interpretação, a argumentação da Ciência do Direito (dogmática), precedentes, formas especiais de argumentos jurídicos e argumentação prática geral (ALEXY, 2005, p. 227).

A argumentação empírica como medida para justificar as premissas não-empíricas da justificação interna. Ou seja, quando determinado enunciado que não é empírico, nem de direito positivo, fundamenta suas razões em justificativas empíricas temos a argumentação empírica na justificação externa.

Os cânones interpretativos se apresentam na justificação externa como forma de fundamentar a interpretação de dadas premissas, principalmente dos textos legais. Fala-se em principalmente porque os cânones podem ser usados "também na fundamentação de normas não positivas, assim como na [...] de muitos outros enunciados jurídicos” (ALEXY, 2005, p. 230). A utilização dos cânones interpretativos pode ser necessária em diversos contextos, “em particular, o conflito de normas, a restrição do campo de aplicação das normas e a fundamentação de normas que não se podem deduzir da lei” (ALEXY, 2005, p. 239).

Importante ressaltar que “um argumento de uma forma só é completo se contém todas as premissas pertencentes a esta forma. A isto se chama o requisito de saturação” (ALEXY, 2005, p. 240). Isto é, quando se afirma, por exemplo, tão somente que determinado fundamento decorre de uma interpretação que expressa o teor da norma, a vontade o legislador ou o fim da norma, esse argumento ainda não está completo. É preciso ainda que haja a saturação. Por isso, “a validade dos argumentos nas diversas formas depende da validade dos enunciados que se estabelecem para dita saturação. Para fundamentar a validade desses enunciados, são necessários argumentos de novas formas” (ALEXY, 2005, p. 234).

Alexy (2005, p. 230-239) vai trabalhar com seis grupos de formas e regras de argumento de interpretação: semântica, genética, histórica, comparativa, sistemática e teleológica. Cada uma das formas de interpretação possui uma função na argumentação. 
As formas da argumentação semântica e genética se referem à vinculação dos órgãos decisores, respectivamente, ao teor da lei e à vontade do legislador. As formas históricas e comparativas permitem a incorporação da experiência do passado e de outras sociedades. A interpretação sistemática serve, entre outras coisas, para eliminar contradições no ordenamento jurídico. Finalmente, as formas teleológicas dão espaço à argumentação prática racional de tipo geral. (ALEXY, 2005, p. 241).

Outro tipo de justificação externa se dá por meio da dogmática jurídica:

A dogmática do Direito é (1) uma série de enunciados que (2) se referem à legislação e à aplicação do Direito, mas que não se podem identificar com sua descrição, (3) estão entre si numa relação de coerência mútua, (4) formam-se e discutem dentro de uma Ciência do Direito que funciona institucionalmente e (5) têm conteúdo normativo. (ALEXY, 2005, p. 249)

A argumentação jurídica dogmática possui, ao menos, seis funções positivas: estabilização, progresso, descarga, técnica, controle e heurística (ALEXY, 2005, p. 258-62).

No que se refere ao uso dos precedentes, são duas as regras: (1) "quando se puder citar um precedente a favor ou contra uma decisão, deve-se fazê-lo”; e (2) “quem quiser se afastar de um precedente, assume a carga da argumentação” (ALEXY, 2005, p. 267).

A primeira regra expõe a importância que o uso dos precedentes tem na argumentação jurídica, já que sempre que se puder citar um precedente o arguente deve fazê-lo. Essa relevância, mais uma vez, decorre do princípio da universalidade (justiça formal) tão recorrente na teoria alexyana. Isto porque, para que se cumpra com o princípio da universalidade é preciso que em casos iguais seja aplicada a mesma ratio decidendi. Mas nesse pensamento há um problema intrínseco: “nunca há dois casos completamente iguais. Sempre se encontra uma diferença” (ALEXY, 2005, p. 265). Assim, “o verdadeiro problema se transfere, por isso, à determinação da relevância das diferenças” (ALEXY, 2005, p. 265).

A apresentação dessas diferenças no discurso jurídico com o fito de enfrentamento do precedente se apresenta comumente em duas possibilidades: do distinguishing e do overruling (ALEXY, 2005, p. 268), e é aqui que a segunda regra ganha valor. Pois, se se admite que haja o afastamento de precedentes, aquele que deseja que o mesmo seja afastado recebe para si o ônus argumentativo. Dessa forma, "tanto o distinguishing quanto o overruling devem ser fundamentados” (ALEXY, 2005, p. 268). Havendo, aqui, a observância do “princípio de inércia perelmaniano que exige que uma decisão só pode ser mudada se se podem apresentar razões suficientes para isso. A satisfação da carga da prova somente pode ser constatada pelos participantes, reais ou imaginários, do discurso” (ALEXY, 2005, p. 265).

Alexy define os argumentos jurídicos especiais como "formas de inferência logicamente válidas” (ALEXY, 2005, p. 269), são os argumentos “que se usam especialmente 


\section{A JUSTIFICAÇÃO INTERNA E EXTERNA DA MÁXIMA DA PROPORCIONALIDADE COMO ARGUMENTO JURÍDICO NAS OBRAS DE ROBERT ALEXY}

na metodologia jurídica, como a analogia, o argumentum a contrario, o argumentum a fortiori e o argumentum ad absurdum (ALEXY, 2005, p. 268-269).

Porém, isso diz pouco, já que qualquer argumento tem estrutura de inferência logicamente válida. O traço típico dos argumentos jurídicos especiais é “a preparação especial das premissas e, frequentemente, a introdução de premissas especiais que muitas vezes permanecem implícitas nas argumentações que ocorrem de fato” (ALEXY, 2005, p. 269). Comumente as formas de argumentos especiais podem-se apoiar em premissas normativas ou em outros argumentos adicionais. Nestes casos "são admissíveis como argumentos adicionais todos os argumentos possíveis no discurso jurídico” (ALEXY, 2005, p. 269).

Os argumentos práticos gerais influenciam na argumentação jurídica, já que esta seria, apara Alexy, um caso especial daquela. Alexy (2005, p. 278) reiteradamente afirma que “a argumentação jurídica depende normalmente da argumentação prática geral e que, por isso, pode-se falar que a argumentação prática geral constitui o fundamento da argumentação jurídica”, sendo este um dos pontos centrais de sua teoria.

Firmados os conceitos necessários para a análise do problema do presente artigo, podese passar para o exame da máxima da proporcionalidade como um argumento jurídico.

\section{A MÁXIMA DA PROPORCIONALIDADE COMO ARGUMENTO JURÍDICO NA JUSTIFICAÇÃO INTERNA E EXTERNA}

Foi visto na seção 2.1 que a máxima da proporcionalidade é utilizada como forma para a resolução de conflitos entre princípios. Aqui já se afasta, assim, a alternativa de aplicação da forma simples da justificação interna, e, portanto, a possibilidade de que se utilizem apenas as suas duas primeiras regras. Isso porque, já que há a ocorrência de mais de uma possibilidade de consequência jurídica - decorrente dos princípios em colisão -, então é preciso que haja um processo de desenvolvimento maior da argumentação para que se justifique o argumento de forma logicamente aceitável.

Destarte, para que se possa se fazer uma subsunção do caso concreto é preciso que haja uma regra que solucione o conflito existente entre os princípios colidentes, uma vez que estes não são mandamentos definitivo, mas apenas prima facie (ALEXY, 2011, p. 107), eles “representam razões que podem ser afastadas por razões antagônicas” (ALEXY, 2005, p. 104), então a solução somente ocorrerá após a aplicação da máxima da proporcionalidade que criará 
o mandamento definitivo ${ }^{5}$ (regra), sendo este o mandamento que irá possibilitar diminuir o grau de abstração e possibilitar o fechamento do silogismo da justificação interna.

Para maior esclarecimento, imagine-se o seguinte caso hipotético: quando da solução do caso concreto, determinado juiz entende que para resolver o problema que lhe é posto, há dois princípios $(\mathrm{Pa}$ e $\mathrm{Pb}$ ) que resolveriam o caso de duas maneiras distintas. Neste caso, já se pode notar que na justificação interna a máxima da proporcionalidade surge quando uma de suas premissas é a de que há a necessidade de aplicação da máxima da proporcionalidade (em um nível mais alto de abstração) e em decorrência disso provoca o aparecimento de outra premissa resultante da aplicação da máxima da proporcionalidade (em um grau mais baixo de abstração) que terá a forma de uma regra. Em síntese, poderíamos dizer que tal justificação interna apresentaria a seguinte estrutura silogística: 1) Há dois princípios colidentes que levaria o caso a resultados distintos; 2) Para a solução do caso é preciso que se resolva o conflito entre os princípios $\mathrm{Pa}$ e $\mathrm{Pb}$; 3) Para resolver o conflito entre os princípios $\mathrm{Pa}$ e $\mathrm{Pb}$, deve-se aplicar a máxima da proporcionalidade; 3.1) Aplica-se a máxima da adequação, caso se consiga qualificar uma medida como adequada e a outra como não-adequada, encontra-se uma solução, passando-se diretamente para a premissa (4), caso contrário segue-se para a máxima da necessidade; 3.2) Aplica-se a máxima da necessidade, caso encontre-se que uma medida é necessária e a outra é desnecessária, chega-se a um resultado satisfatório, passando-se para a premissa (4), caso contrário segue-se para a máxima da proporcionalidade em sentido estrito (sopesamento); 3.3) Aplicam-se as leis do sopesamento, caso haja resultado satisfatório, passase para a premissa (4), caso não se encontre, resolve-se discricionariamente; 4) Como resultado da aplicação da máxima da proporcionalidade, chega-se à seguinte regra: dada as condições fáticas F1 e F2, Pa tem precedência sobre Pb, gerando a consequência jurídica C; e 5) Desse modo, visto que no caso concreto estão presentes as condições fáticas F1 e F2, então Pa tem precedência sobre $\mathrm{Pb}$, e a solução deve ser $\mathrm{C}^{6}$.

\footnotetext{
5 “Como resultado de todo sopesamento que seja correto do ponto de vista dos direitos fundamentais pode ser formulada uma norma de direito fundamental atribuída, que tem estrutura de uma regra e à qual o caso pode ser subsumido" (ALEXY, 2011, p. 102).

${ }^{6}$ Em razão das regras 4 e 5 da justificação interna, a justificação pode ser mais complexa, podendo haver premissas com maior ou menor grau de abstração, além de outros tipos de argumentos. Ademais, o salto entre as premissas (2) e (4) dependerá de quantas fases da máxima da proporcionalidade serão necessárias para que se chegue à regra que solucionará o conflito entre os princípios. Porém, para fins didáticos, o esquema será útil para que se entenda como a máxima da proporcionalidade pode se apresentar na justificação interna, bem como será ele o paradigma utilizado para aprofundamentos no momento de análise da justificação externa. Pois bem, se a justificação interna ajuda na exposição de como a máxima da proporcionalidade se apresenta na decisão, e se ela segue logicamente das premissas expostas argumentação, a avaliação da correção dessas premissas somente poderá ser feita através da justificação externa. É preciso destacar, ainda, que as premissas presentes em (3),
} 


\section{A JUSTIFICAÇÃO INTERNA E EXTERNA DA MÁXIMA DA PROPORCIONALIDADE COMO ARGUMENTO JURÍDICO NAS OBRAS DE ROBERT ALEXY}

Antes de se adentrar mais a fundo a análise da justificação externa da máxima da proporcionalidade é preciso destacar que cada uma das fases tende a possuir uma forma mais próxima à determinada categoria de argumentação. No entanto, é preciso ressaltar a relação próxima existente entre as categorias de argumentos jurídicos, o que explica que umas tangenciam as outras. Portanto, a escolha de cada categoria foi a que pareceu ser a mais adequada, ou, ao menos, a potencialmente mais recorrente para cada tipo de máxima com referência aos tipos de justificação externa.

Dito isso, a partir de agora poderá será feita a análise sobre qual tipo de argumentação jurídica pode ser classificada, na justificação externa, a (I) máxima da proporcionalidade em sentido lato, (II) a máxima da adequação, a (III) máxima da necessidade e, por fim, da (IV) a máxima da proporcionalidade em sentido estrito.

\subsection{Justificação externa da máxima da proporcionalidade em sentido lato}

A pergunta a ser respondida na justificação externa, pois, deve ser: como posso justificar e averiguar a correição da premissa que sustenta que para resolver o conflito entre os princípios $\mathrm{Pa}$ e $\mathrm{Pb}$ deve-se utilizar a aplicação da máxima da proporcionalidade? Encontraramse três respostas em potencial. A justificação externa da premissa (3) pode se dar através da dogmática jurídica, do uso de precedentes e como forma de argumento jurídico especial.

\subsubsection{Máxima da proporcionalidade em sentido lato como argumento dogmático}

Aqui se defenderá que primeiramente a premissa (3) foi justificada através da dogmática jurídica, sendo Alexy um dos autores principais, senão o principal, para que isso ocorresse. Embora Alexy fundamente a existência da máxima da proporcionalidade como decorrente da natureza dos princípios (ALEXY, 2011, p. 120), isso não exclui o fato de que primeiro ela surgiu analiticamente através da dogmática.

A máxima da proporcionalidade em sentido lato, como é típico da dogmática (nos moldes da definição dada por Alexy), é uma série de enunciados que se referem à normatividade e à aplicação do Direito, mas que não se confunde com uma mera descrição legislativa ou da aplicação jurídica, possui uma coerência mútua e institucionalizada por quem dela se vale e tem

objeto principal do presente estudo, não se enquadram nem em regras de direito positivo nem são enunciados empíricos, o que significa que sua justificação externa é possível através da argumentação jurídica. 
conteúdo normativo, que é o de que havendo conflito entre princípios, tal conflito deve ser resolvido por meio da máxima da proporcionalidade.

Destaque-se, também, que a máxima da proporcionalidade apresenta características funcionais da dogmática. Isto porque ela estabiliza o conteúdo do conceito de máxima da proporcionalidade, evitando que se discuta sempre o que se deve fazer quando se está diante de uma colisão de princípios; possibilita o progresso e ampliação das discussões acerca de qual princípio deve prevalecer em determinadas condições fáticas e jurídicas; tem o papel também de descarga, já que uma vez que a dogmática aceita, de maneira mais ou menos estabilizada, a máxima da proporcionalidade como meio apto a solucionar o conflito entre princípios, aquele que discordar é de quem será o ônus argumentativo; também possui a função técnica, vez que o conceito e o desenvolvimento de formação dos conceitos e etapas se deram através de estudos dogmáticos e são passados, também, por meio da dogmática; apresenta importante função de controle das decisões, visto que com a aplicação da máxima pode-se ter acesso de maneira mais clara e racional sobre as razões que levaram a decisão de precedência entre um princípio e outro; e, por fim possui a função heurística dado que a máxima apresenta novas soluções para conflitos existentes e que pode mudar de resposta sempre que as condições fáticas ou jurídicas assim determinarem.

Assim sendo, é possível que a justificação de correção da premissa (3) se dê no âmbito da dogmática jurídica. No entanto, a partir do momento em que julgados se utilizam da máxima da proporcionalidade, a correição do argumento da premissa (3) também pode ser justificada como respeito ao precedente. É o será exposto a seguir.

\subsubsection{Máxima da proporcionalidade em sentido lato como argumento de uso de precedente}

Quando se falou na máxima da proporcionalidade justificada externamente por meio da dogmática jurídica estava-se referindo, primordialmente, a uma aplicação da máxima que ainda não havia sido feita, ao menos não de forma estruturada analiticamente, pelos tribunais. No entanto, a partir do momento que os órgãos de decisão passam a utilizar da máxima da proporcionalidade como ratio para a solução jurídica de um caso, então passa a haver precedentes que podem servir de justificação externa sobre determinado assunto ${ }^{7}$.

\footnotetext{
${ }^{7} \mathrm{O}$ mesmo pode ocorrer em quaisquer das justificações externas existentes entre as submáximas da adequação, necessidade e proporcionalidade em sentido estrito. Embora se sustente mais a frente tipos específicos de argumentação jurídica aptos a justificar externamente as premissas das máximas parciais, sempre que houver alguma decisão em que já se aplicou alguma(s) da(s) máxima(s), poder-se-á utilizar o precedente como forma adequada de justificação externa, nos moldes de como aqui exposto.
} 


\section{A JUSTIFICAÇÃO INTERNA E EXTERNA DA MÁXIMA DA PROPORCIONALIDADE COMO ARGUMENTO JURÍDICO NAS OBRAS DE ROBERT ALEXY}

Por exemplo, se no caso do nosso julgamento hipotético um Tribunal já tivesse decidido que aquele era um caso em que havia conflito entre princípios (1), que era preciso resolvê-lo por meio da aplicação da máxima da proporcionalidade (2) e que ao aplicar a máxima (3), chegou-se ao resultado da regra (4), então, o juiz deveria se referir ao precedente.

Decerto, ao citar o precedente o juiz pode concordar ou não com seu uso para a solução do caso concreto. Se concordar, sua carga argumentativa pode ser mais leve do que seria caso ele precisasse tomar uma decisão inédita, já que a justificativa externa para a correção das premissas poderá ser feita através do uso do precedente. Caso discorde da utilização do precedente, ele deve aplicar o distinguishing ou overruling e, assim, assumir o encargo de superar o princípio da inércia, em deferência à segunda regra do uso de precedentes.

Ocorre que o uso da regra (3) ainda pode ser fundamentado na justificação externa também como sendo um argumento jurídico especial. É o que se sustenta a seguir.

\subsubsection{Máxima da proporcionalidade em sentido lato como argumento jurídico especial}

A forma com que a máxima da proporcionalidade vem sendo aplicada repetidamente nos processos decisórios jurídicos tem possibilitado que a justificação externa da premissa (3) passe a poder ser categorizado como sendo um argumento jurídico especial.

Isso porque a máxima da proporcionalidade em sentido lato exige que as formas de inferência realizadas internamente através das três máximas parciais precisem ser logicamente válidas. A aplicação da máxima da adequação, da necessidade ou da proporcionalidade em sentido estrito, precisa ter, em seu interior, silogismos próprios por meio de um processo pelo qual, através de determinados dados, chega-se a uma conclusão logicamente válida.

O critério de que os argumentos jurídicos especiais são usados notadamente na metodologia jurídica também está satisfeito. A máxima de proporcionalidade tem uma especial utilização na estrutura da argumentação jurídica, tanto que tem sido utilizada largamente nas decisões e postulações jurídicas, não apenas como forma de solução do caso concreto, mas também como maneira de justificar as escolhas entre as determinações de princípios colidentes de forma mais racional.

O terceiro critério fala da preparação especial das premissas utilizadas na cadeia argumentativa, que podem ser normativas ou de outro tipo de argumento jurídico. Pois bem, na aplicação da máxima da proporcionalidade, as premissas que são postas para fundamentar o raciocínio também são inerentes à argumentação jurídica, isso será mais bem demonstrado logo 
à frente. No entanto, importante ressaltar que essa preparação ocorre metodologicamente em cada etapa da aplicação das máximas.

Do mesmo modo que acontece na analogia, no argumentum a contrario, no argumentum a fortiori e no argumentum ad absurdum, exemplos de argumentos jurídicos especiais citados por Alexy (2005, p. 268), também tem ocorrido na máxima da proporcionalidade em sentido amplo. Podendo, portanto, ser uma forma de justificar externamente o uso da premissa (3) como sendo o fruto do uso de um argumento jurídico especial.

\subsection{Justificação externa da máxima da adequação}

Este tópico irá se dedicar a estudar a justificação externa da aplicação da máxima da adequação, premissa 3.1 do silogismo que está sendo base para o presente estudo.

A fim de facilitar o entendimento do tema, toma-se como exemplo o caso citado por Alexy quando ele vai explicar a máxima da adequação em Teoria dos Direitos Fundamentais. Naquela oportunidade Alexy (2011, p. 588-589) narra a seguinte situação:

Um cabeleireiro colocou, sem permissão, uma máquina de venda automática de
cigarros em seu estabelecimento. Diante disso, as autoridades administrativas
impuseram-lhe uma multa por descumprimento da lei sobre o comércio no varejo.
Essa lei exigia uma permissão, que só seria concedida se o requerente demonstrasse
"a necessária expertise", a qual poderia ser obtida por meio de um curso
profissionalizante como comerciante, de uma prática de muitos anos em um
estabelecimento comercial ou de um exame especial, no qual seriam testados
conhecimentos técnico comerciais. [...]. O Tribunal Superior Estadual de Saarbrücken
[...] considerou inconstitucional a exigência de uma demonstração de expertise
comercial nos casos de instalação de simples máquinas automáticas e suscitou uma
prejudicial de inconstitucionalidade perante o Tribunal Constitucional Federal. O
Tribunal Constitucional Federal chegou à conclusão de que a exigência de uma prova
de expertise para qualquer comércio de qualquer mercadoria - ou seja, também para a
exploração de máquinas automáticas para vender cigarros - viola a liberdade
profissional garantida pelo art. 12 , § 1 o , da Constituição alemã. Sua fundamentação
baseia-se essencialmente no fato de que a exigência de uma prova de competência
comercial no caso da exploração de uma máquina automática para vender cigarros
não é adequada para proteger o consumidor contra prejuízos à sua saúde ou contra
prejuízos econômicos. Por essa razão, essa exigência seria proibida pela máxima da
adequação e violaria o direito fundamental à liberdade profissional. No caso analisado percebe-se que dois são os princípios em colisão: liberdade profissional $(\mathrm{Pa})$ e proteção ao consumidor $(\mathrm{Pb})$. O que foi argumentado na decisão do Tribunal Constitucional Alemão é que a medida (M) de se exigir a prova de expertise do comerciante, que explora economicamente uma máquina automática de venda de cigarro, era por um lado uma medida inadequada para fomentar a proteção ao consumidor, e por outro atrapalhava a otimização do princípio da liberdade profissional (ALEXY, 2011, p. 590).Transpondo tal 


\section{A JUSTIFICAÇÃO INTERNA E EXTERNA DA MÁXIMA DA PROPORCIONALIDADE COMO ARGUMENTO JURÍDICO NAS OBRAS DE ROBERT ALEXY}

argumentação para uma análise de justificação interna, nota-se que ela se enquadra no modelo silogístico apresentado na seção 4 deste trabalho. Há dois princípios colidentes que levaria a resultados distintos (premissa 1); para a solução do caso é preciso que se resolva o conflito entre os princípios da liberdade profissional (Pa) e da proteção ao consumidor (Pb) (premissa 2); para resolver o conflito entre os princípios deve-se aplicar a máxima da proporcionalidade em sentido lato (premissa 3); por isso, primeiro deve-se aplicar a máxima da adequação (premissa 3.1); como resultado da máxima da adequação, chega-se à seguinte regra: uma norma que exija a comprovação de expertise (F1) para a exploração de uma máquina automática de venda de cigarros (F2) viola o direito fundamental à liberdade profissional, tendo como consequência jurídica (C) a sua inconstitucionalidade (premissa 4).

Vista a argumentação da justificação interna, pode-se direcionar o estudo para o foco desta seção que é como justificar externamente a aplicação da máxima da adequação (3.1).

O que está sendo discutido para a solução do caso está no campo de conflito de normasprincípios, em que se discute a restrição da aplicação dessas normas, bem como da fundamentação de regras decorrentes de tais princípios que não se pode deduzir diretamente da lei. Desse modo, o uso de cânones jurídicos como forma de justificação externa se mostra apropriado para fundamentar a aplicação da máxima da adequação. No entanto, são vários os cânones de interpretação, e, por isso, é preciso demonstrar qual deles se mostra mais relevante para a justificação externa da máxima da adequação.

Observe que para fundamentar sua decisão acerca da aplicação da adequação, o tribunal fez as seguintes afirmações: (I) a exigência de uma prova de competência comercial no caso da exploração de uma máquina automática de venda de cigarros não é adequada para proteger o consumidor e atrapalha a otimização do princípio da liberdade profissional; e (II) deve-se proteger o consumidor contra prejuízos à sua saúde ou contra prejuízos econômicos e otimizar o princípio da liberdade profissional. As afirmações contidas em (I) são notadamente afirmações empíricas, as contidas em (II), por sua vez, são enunciados normativos. A união dessa forma de argumento permite que se chegue a um tipo especial de argumentação jurídica baseada nos cânones de interpretação: a argumentação interpretativa teleológica objetiva. Veja, nesse caso há um estado de coisas a se perseguir (defesa do consumidor e liberdade profissional) e a interpretação é decorrente de premissas empíricas que se mostram necessárias para o correto julgamento e o alcance do estado de coisas pretendido. 
Ainda que com outro conceito de princípios, Alexy em “Teoria da Argumentação Jurídica” faz uma relação entre a argumentação teleológica objetiva e seu uso em casos envolvendo princípios jurídicos quando afirma que "geralmente, para a descrição de estado de coisas são necessárias normas de tipo geral ou princípios. [...] A argumentação teleológica se torna, com isso, argumentação a partir de princípios”.

Como esse estado de coisas não são objetivos que se referem a pessoas que realmente existiram, mas sim, a objetivos prescritos objetivamente no contexto do ordenamento jurídico vigente, não se pode falar de interpretação genética. Não há, também como se classificar como interpretação sistemática, pois em Alexy (2005, p. 235) tal interpretação se restringe às relações lógicas entre as normas, o que é insuficiente para justificar a preferência de um princípio sobre outro por meio da máxima da adequação, já que logicamente os princípios colidentes não se excluem, pois no modelo de Alexy, em Teoria dos Direitos Fundamentais, os princípios quando colidem cedem um ao outro, sob determinadas condições fáticas, continuando a conviver logicamente dentro do sistema, mesmo que pontualmente não seja aplicado, algo que ocorre de forma diferente no âmbito no conflito entre as regras que se resolve com sua exclusão do ordenamento (ALEXY, 2011, p. 93).

Da mesma forma, não se trata, neste momento da justificação interna, de discussão semântica, haja vista que não se discute o significado dos princípios, mas sim qual será o meio e o fim que o ordenamento prescreve em determinadas situações. Não pode ser fundamentada principalmente em uma interpretação comparativa, pois a máxima da adequação é baseada em relação de meios e fins da comunidade em que vige o direito positivo aplicado no caso, e, embora possa vir a servir de complemento para fundamentar determinada interpretação teleológica objetiva (na justificação da justificação da interpretação teleológica objetiva), ela não é suficiente para firmar uma justificativa externa sozinha da máxima da adequação. O mesmo pode-se dizer sobre a interpretação histórica, pois embora possa ser útil na justificação das premissas integrantes da interpretação teleológica objetiva, ela somente será útil em um $2^{\circ}$ grau, e, não para justificar diretamente a máxima da adequação.

Portanto, pode-se fazer uso da interpretação teleológica objetiva para se fundamentar adequadamente $^{8}$, por meio da justificação externa, a máxima da adequação. Algo próximo acontece com a máxima da necessidade. É o que se passa a expor.

\footnotetext{
${ }^{8}$ Em razão do requisito da saturação, é possível que outros argumentos complementem a justificação externa da máxima da adequação. No entanto, o que se aduz no presente é que a argumentação teleológica objetiva será o núcleo principal de uma justificação externa apropriada para a máxima da adequação.
}

Revista de Teorias da Justiça, da Decisão e da Argumentação Jurídica | e-ISSN: 2525-9644 | Salvador | v. 4 | n. 1 | p. 96 - 118 | 


\section{A JUSTIFICAÇÃO INTERNA E EXTERNA DA MÁXIMA DA PROPORCIONALIDADE COMO ARGUMENTO JURÍDICO NAS OBRAS DE ROBERT ALEXY}

\subsection{Justificação externa da máxima da necessidade}

Assim como foi feito com a análise da máxima da adequação, para facilitação do estudo, tomar-se-á como exemplo um dos casos citados por Alexy em “Teoria dos Direitos Fundamentais” quando ele vai explicar a máxima da necessidade. O caso da vez é o seguinte:

Uma portaria do Ministério [...] continha a proibição de comercialização de doces que, embora contivessem chocolate em pó, eram feitos sobretudo de flocos de arroz e não eram, portanto, produtos genuinamente de chocolate. O objetivo dessa portaria era proteger o consumidor contra compras equivocadas. O Tribunal Constitucional Federal observou que uma tal proibição de comercialização de mercadorias seria inteiramente adequada para proteger o consumidor. Se há uma proibição de que algo seja comercializado, o risco de que ele seja comprado por engano é pequeno. No entanto, a proibição de comercialização não seria necessária. Haveria uma medida igualmente adequada e, ao mesmo tempo, menos invasiva. Um dever de identificação no rótulo poderia combater o perigo de confusões e equívocos "de maneira igualmente eficaz, mas de forma menos invasiva" (ALEXY, 2011, p. 591).

Aqui novamente se tem a colisão dos princípios da liberdade profissional (Pa) e o princípio da proteção do consumidor $(\mathrm{Pb})$. Ao analisar tal argumentação, também se verifica que ela se enquadra no modelo silogístico apresentado anteriormente. Observe-se: há dois princípios colidentes que levaria a resultados distintos (premissa 1); para a solução do caso é preciso que se resolva o conflito entre os princípios da liberdade profissional (Pa) e da proteção ao consumidor $(\mathrm{Pb})$ (premissa 2); para resolver o conflito entre os princípios deve-se aplicar a máxima da proporcionalidade em sentido lato (premissa 3); aplicou-se a máxima da adequação, mas não alcançou-se resultado, pois ambas as medidas eram adequadas (premissa 3.1); passase então a aplicação da máxima da necessidade (premissa 3.2); como resultado da máxima da necessidade, chega-se à seguinte regra: uma norma que proíba a comercialização de doces que, embora contenham chocolate em pó, são feitos sobretudo de flocos de arroz (F1), restringe em demasia o princípio da liberdade profissional de forma desnecessária (F2) e, por isso, viola o direito fundamental à liberdade profissional, já que o dever de identificação no rótulo alcança o princípio da proteção ao consumidor de forma também adequada e não intervém de forma tão intensa no princípio da liberdade profissional, trazendo como consequência jurídica (C) a sua ilegalidade (premissa 4).

Para justificar externamente a aplicação da máxima da necessidade, nota-se grande semelhança com a justificação externa da máxima da adequação. Isso porque, as duas máximas têm estruturas bastante próximas. Ambas cuidam das possibilidades fáticas do processo de aplicação da máxima da proporcionalidade (ALEXY, 2011, p. 118). E igualmente dizem 
respeito a uma relação meio-fim (ALEXY, 2011, p. 592) em que as constatações empíricas e o estado de coisas almejado são importantes quando de sua justificação externa.

Desse modo, note-se que para fundamentar sua decisão acerca da aplicação da necessidade, o Tribunal Constitucional Federal Alemão fez as seguintes afirmações: (I) a comercialização de doces que, embora contenham chocolate em pó, são feitos sobretudo de flocos de arroz, podem enganar consumidores quanto à sua natureza; (II) o dever de identificação no rótulo do tipo do produto alcança o princípio da proteção ao consumidor, mas não intervém de forma tão intensa no princípio da liberdade profissional; e (III) deve-se proteger o consumidor contra perigo de confusões e equívocos na hora da escolha do produto a ser consumido e proteger a liberdade do exercício profissional.

As afirmações (I) e (II) são de natureza empírica. As considerações existentes em (III), por sua vez são enunciados normativos. Como já foi visto, a argumentação teleológica objetiva possui justamente essa característica de necessitar de premissas que apresentem, por um lado, constatações empíricas e por outro um estado de coisas a ser perseguido a fim de alcançar um resultado proporcional para o caso concreto. Na decisão em estudo, há novamente um estado de coisas a se perseguir (defesa do consumidor e liberdade profissional) e a interpretação é decorrente de premissas empíricas que se mostram necessárias para o correto julgamento e o alcance do estado de coisas pretendido.

Portanto, aqui também é o caso do uso da interpretação teleológica objetiva como forma idônea para justificar externamente o uso da máxima da necessidade, sendo que as observações contidas no tópico anterior em relação à máxima da adequação e a interpretação teleológica objetiva, também são de proveito para a análise na máxima da necessidade.

Porém, nem sempre as máximas da adequação e necessidade são suficientes para resolver os casos que chegam aos tribunais. Quando isso ocorre, é preciso que se aplique a máxima da proporcionalidade em sentido estrito, que também poderá ser fundamentada por meio de expedientes de justificação externa, como se verá no tópico seguinte.

\subsection{Justificação externa da máxima da proporcionalidade em sentido estrito}

O que se busca neste tópico do presente trabalho é saber qual das formas de argumentos jurídicos na justificação externa é adequada para justificar a premissa 3.3 do silogismo paradigma do nosso estudo. Conforme foi visto na seção 2 deste trabalho, são duas as leis do sopesamento pertencentes à máxima da proporcionalidade em sentido estrito: a primeira trata-

Revista de Teorias da Justiça, da Decisão e da Argumentação Jurídica | e-ISSN: 2525-9644 | Salvador | v. 4 | n. 1 | p. 96 - 118 | 


\section{A JUSTIFICAÇÃO INTERNA E EXTERNA DA MÁXIMA DA PROPORCIONALIDADE COMO ARGUMENTO JURÍDICO NAS OBRAS DE ROBERT ALEXY}

se de uma lei material (substantiva) e a segunda uma lei formal (epistêmica). Por serem de naturezas distintas, serão examinadas separadamente nos tópicos que seguem.

\subsubsection{Primeira lei do sopesamento}

Na linguagem da argumentação jurídica, pode-se notar que a estrutura da cadeia argumentativa da primeira lei do sopesamento em muito se assemelha ao tipo de justificação externa chamada por Alexy de “argumento jurídico especial”, tal como ocorreu com a última forma de justificação externa da máxima da proporcionalidade em sentido lato.

A primeira característica dos argumentos jurídicos especiais diz que eles são formas de inferência logicamente válidas. A primeira lei do sopesamento ao dizer que "quanto maior for o grau de não-satisfação ou de afetação de um princípio, tanto maior terá que ser a importância da satisfação do outro”, exige que entre suas premissas de grau de satisfação, nãosatisfação, importância e afetação, também haja inferências que possam ser logicamente avaliadas, e possuindo como resultado uma relação lógica válida, através de processos adequados de inferências. "O modelo de sopesamento como um todo oferece um critério, ao associar a lei de colisão à teoria da argumentação jurídica racional. A lei de colisão diz o que deve ser fundamentado de forma racional” (ALEXY, 2011, p. 173-174).

A segunda característica é seu notável uso na metodologia jurídica. Alexy (2011, p. 144), vale dizer que “é possível falar tanto de uma colisão e de um sopesamento entre princípios quanto de uma colisão e de um sopesamento entre valores”. No entanto, é inegável que a primeira lei do sopesamento tem uma larga utilização na metodologia jurídica, podendo ser encontrada em diversos julgados e discursos jurídicos, de maneira que não há exagero em entendê-la como sendo um tipo que possui uso especial na metodologia jurídica atual, tanto quanto o argumentum a contrario e o argumentum a fortiori, por exemplo.

A terceira característica é a preparação especial das premissas utilizadas na cadeia argumentativa, que podem ser normativas ou de outro tipo de argumento jurídico, o que pode ser visto na lei material do sopesamento por meio das três etapas indicadas por Alexy (2011, p. 594). Haverá, primeiro, uma premissa que reflita o grau de não-satisfação ou afetação de um dos princípios, depois uma premissa em que seja o resultado da avaliação da satisfação do princípio contraposto, e, por fim, a resposta da estimava da importância da satisfação do princípio colidente justifica em face da afetação ou a não-satisfação do outro princípio. 
É possível, pois, perceber que a primeira lei do sopesamento pode surgir na justificação externa como um argumento jurídico especial e, assim, torna-se possível avaliar sua correição. No entanto, a segunda lei do sopesamento apresenta características típicas de outro tipo de forma de argumento da justificação externa, como se demonstrará a seguir.

\subsubsection{Segunda lei do sopesamento}

O desafio da lei epistêmica do sopesamento em muito se aproxima ao problema que a argumentação empírica busca resolver na justificação externa. Ora, este tipo de argumentação busca justificar as premissas que são não-empíricas e aquelas que não são oriundas de normas positivadas, mas que se justificam por meio de pressupostos empíricos. Veja, a premissa da justificação interna 3.3 diz que "não havendo solução na premissa 3.2, aplicam-se as leis do sopesamento”. Uma dessas leis é a que postula um grau de certeza das premissas nas quais essa intervenção se baseia. O que se defende aqui é que esse grau de certeza pode ser alcançado (justificado externamente) através da argumentação empírica.

Alexy (2011, p. 591), ao citar a questão da segunda lei do sopesamento, narra o seguinte caso:

O Tribunal [...] tinha que decidir se a criminalização da fabricação, comercialização, disseminação e aquisição de produtos derivados de cannabis seria compatível com a liberdade geral de ação e com a liberdade pessoal. Era também necessário indagar se uma liberação da cannabis, como um meio menos gravoso em relação à liberdade, não poderia afastar os perigos associados a essa droga e a seu comércio ilegal de forma tão ou mais eficiente que uma criminalização geral. A resposta do tribunal baseou-se na tese de que não existem "conhecimentos fundados cientificamente que decidam indubitavelmente em favor de um ou de outro caminho".

Neste caso, a premissa de que não se possuía conhecimento suficiente para julgar a causa, pressupunha a necessidade de se saber empiricamente sobre "os perigos associados a essa droga [cannabis] e a seu comércio”, algo que só seria possível conhecer com grau de certeza suficiente com a ajuda do avanço de outras ciências, o que, quando da decisão, não era possível saber, e, por conseguinte, não era possível, também, fazer juízo jurídico seguro o bastante para o sopesamento. Assim, a questão da justificação externa por meio da argumentação empírica nesses casos se mostra relevante, já que “em numerosas discussões jurídicas, a apreciação dos fatos desempenha papel decisivo. Se há acordo sobre os enunciados normativos que se devem aceitar, a decisão depende unicamente de quais fatos se devem tomar como base” (ALEXY, 2005, p. 229). 


\section{A JUSTIFICAÇÃO INTERNA E EXTERNA DA MÁXIMA DA PROPORCIONALIDADE COMO ARGUMENTO JURÍDICO NAS OBRAS DE ROBERT ALEXY}

Portanto, a argumentação jurídica externa empírica pode ser um meio adequado de se estruturar a segunda lei do sopesamento como argumento jurídico, o que faz com que se alcance o quanto se pretendia realizar com o presente trabalho.

\section{CONSIDERAÇÕES FINAIS}

O presente trabalho procurou fazer um entrelaçamento do conceito da máxima da proporcionalidade com os conceitos apresentados por Alexy em sua teoria da argumentação jurídica. Convertendo a máxima da proporcionalidade em um argumento jurídico, foi possível fazer uma análise teórica de como tal conceito pode surgir no discurso argumentativo jurídico.

Com isso, argumentou-se no sentido de que a máxima da proporcionalidade em sentido amplo surgiu, primeiramente, como argumento dogmático, pois, embora já tivesse havido decisões com o teor da máxima estudada, ou que ela, para Alexy, seja fundamentada pela natureza dos princípios, sua construção analítica da forma como vem sendo usada, começou por meio de estudos dogmáticos e só depois alcançou a jurisprudência. A partir disto, ao alcançar os tribunais, a máxima da proporcionalidade passou a ser passível de justificação externa por meio do uso de precedentes, já que com o desenvolvimento da máxima, alguns conflitos entre princípios foram sendo resolvidos, criando precedentes que passaram a precisar ser considerados nas decisões futuras. Ainda como uma análise de desenvolvimento da aplicação da teoria, chegou-se a possibilidade da máxima da proporcionalidade ser justificada externamente através dos chamados argumentos jurídicos especiais, tais como a analogia e os argumentos a contrario, a fortiori e ad absurdum.

Passando-se à análise das máximas parciais, chegou-se à conclusão de que as máximas da adequação e necessidade, por apresentarem estruturas em que há a necessidade de formulação de premissas empíricas combinadas com premissas que apresentam um estado de coisas a ser alcançado, seriam adequadamente fundamentadas externamente por meio do cânone jurídico de interpretação chamado de teleológico objetivo, já que este apresenta características próximas às exigidas pelas duas primeiras máximas da proporcionalidade.

A máxima da proporcionalidade em sentido estrito foi analisada por meio de suas duas leis: a lei material e a lei epistêmica. Quanto se levanta uma premissa na justificação interna referente à lei material, foi sustentado que a mesma poderia ser justificada externamente tratando-a como um argumento jurídico especial. Já a lei epistêmica foi argumentado que seria 
adequadamente justificada externamente, na medida em que fosse avaliadas como argumentação jurídica externa de natureza empírica.

Assim sendo, entende-se que o estudo alcançou os objetivos traçados por ter entrelaçado a noção de máxima da proporcionalidade trazida por Alexy em “Teoria dos Direitos Fundamentais” e sua concepção de argumentação jurídica, mediante uma análise da justificação interna e externa da mencionada máxima como argumento jurídico.

\section{REFERÊNCIAS}

ALEXY, R. Teoria da argumentação jurídica: a teoria do discurso racional como teoria da fundamentação jurídica. Tradução de Zilda Hutchinson Schild Silva. Revisão técnica da tradução e introdução à edição brasileira Claudia Toledo. 2. ed. São Paulo: Landy Editora, 2005. ALEXY, R. Teoria dos Direitos Fundamentais. Tradução de Virgílio Afonso da Silva. 2. ed. São Paulo: Malheiros, 2011.

GEREMBERG, A. L. W. A teoria compreensiva de Robert Alexy: a proposta do ‘trialismo'. (Tese de Doutorado) - Departamento de Direito, Pontifícia Universidade Católica do Rio de Janeiro. Rio de Janeiro. 2006.

GORZONI, P. Entre o princípio e a regra: teoria dos direitos fundamentais. Novos estud. CEBRAP, São Paulo, n. 85, p. 273-279, 2009. Disponivel em: <https://goo.gl/K6gVFn>. Acesso em: 13 fevereiro 2018.

KLAT, M.; MEISTER, M. A Máxima da Proporcionalidade: um elemento estrutural do constitucionalismo global. Observatório da Jusrisdição Constitucional, Brasília, v. VII, n. 1, p. 23-41, jan/jun 2014. Disponivel em: <https://goo.gl/36H4zD>. Acesso em: 13 fevereiro 2018.

PAULA, A. F. L. D. Fundamentação da decisão judicial: justificação interna e externa. Revista do CAAP, Belo Horizonte, v. VIII, n. 2, jul-dez 2009. Disponivel em: $<$ https://goo.gl/XZpa5A>. Acesso em: 10 fevereiro 2018.

Revista de Teorias da Justiça, da Decisão e da Argumentação Jurídica | e-ISSN: 2525-9644 | Salvador | v. 4 | n. 1 | p. 96 - 118 | 
PEDRON, F. Q. A ponderação de princípios pelo STF: balanço crítico. Revista CEJ, Brasília, v. XII, n. 40, p. 20-30, jan./mar. 2008. Disponivel em: <https://goo.gl/fMcnyP>. Acesso em: 25 fevreiro 2018.

PEREIRA, B. R. O uso da proporcionalidade no Supremo Tribunal Federal: análise dos votos do ministro Gilmar Mendes (2004-2006). Dissertação (Mestrado em Direito do Estado) - Faculdade de Direito, Universidade de São Paulo. São Paulo. 2009. 